\title{
UN MORISCO ASTRÓLOGO, EXPERTO EN MUJERES (MS. JUNTA XXVI)
}

\author{
A Wasma'a Chorbachi, \\ mi antigua compañera de estudios \\ de Harvard, que una tarde afortunada \\ me introdujo al misticismo musulmán \\ y cambió para siempre mi vida.
}

Estamos a mediados del siglo XVI. Una muchacha, oriunda de las inmediaciones de Almonacid de la Sierra, está próxima a casarse y desea saber la suerte que le deparan los astros en su nuevo estado. Se dirige subrepticiamente donde el maestro astrólogo Abdala de Cosuenda, quien la recibe con toda suerte de cautelas: no quiere arriesgar ni la intimidad de la joven en trance de averiguaciones futurológicas ni su propia vida a manos del Santo Oficio. Son los "tiempos recios" que con amarga simpatía ha denunciado la Madre Teresa de Ávila. Nuestra muchacha, visiblemente ansiosa, anticipa en su imaginación lo que le dirá el estrellero en lo tocante a su inminente matrimonio, a sus hijos, a su estado financiero, a su salud. Sólo tiene un problema: ignora el día y el mes de su nacimiento, que hace veinte años costó la vida a su madre. Duda mucho que su interlocutor sea capaz de levantar un horóscopo sin estos datos. Pero el sortílego se las arreglará para averiguar la constelación de su clienta prescindiendo de estos "detalles" que tanto habrían preocupado a sus ilustres antecesores Claudio Ptolomeo y Aben Ragel. La muchacha le proporciona en seguida los únicos datos que precisa el estrellero para su tarea judiciaria: su nombre y el de su madre. Con esta parca información, se aplica a unas cábalas que sobrecogen a la demandante. Aunque no sabe leer, sí reconoce, con angustia instintiva, las letras del alifato sobre las que computa el morisco, y recuerda 
que su uso llevó a la cárcel a uno de sus tíos más queridos. Pero su temor visceral cede rápidamente ante su decisión firme de familiarizarse con su destino estelar. Abdala ya está listo. Ha averiguado el signo astrológico de su clienta y se dispone a orientarla. A pesar de que la consulta se tiene que dar en el más estricto secreto, el develador de futuros tiene un sólido prestigio en la comunidad. Es que es un morisco astrólogo experto en mujeres. Y la joven, que todavía tiembla, comienza a oír de sus labios lo que las estrellas determinan para su vida modesta de aldeana. Ya veremos que será increíblemente afortunada.

Hemos intentado evocar brevemente las emociones y las angustias que habrá suscitado el texto astrológico que motiva nuestro presente estudio entre los moriscos del siglo Xvi que serían sus usuarios. El tratado, que forma parte de un códice aljamiado de sortilegios (Junta XXVI, fols. 3 Ir al 84r), de autor anónimo, recibe el título de su primera línea: “Exte ex alquiteb quextá en él el conto de Du-l-carnáin" (Éste es el libro que está en él el cómputo de Alejandro Magno $)^{1}$, y parece ser que perteneció a un tal Abdala, natural de Cosuenda, si es que damos fe a la firma posesiva que encabeza el códice ("Košuwenda 'Abd Allāh'). El misterioso Abdala, si es que llegó a servirse del manuscrito de su propiedad, debió haber sido un sortílego muy capaz en achaques de adivinación del provenir. Su texto, que vamos a editar en su totalidad, abarca las más distintas formas de la futurología musulmana: el sistema cabalístico de valoración de las letras arábigas para fines

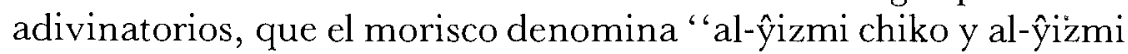
mayor"; los "alborŷes" (constelaciones o signo astrológicos) de los hombres y de las mujeres; la suerte del "paliko"' (especie de dado rectangular arrojadizo cuyos puntos hay que decodificar según las instrucciones del códice); la oniromancia o valor adivinatorio de los sueños, así como los pronósticos sobre el tiempo y los sucesos históricos, tomando como punto de partida los truenos, eclipses, auroras boreales, estrellas fugaces y la entrada del año.

Nuestro autor morisco, aunque de manera modesta, forma tradición con los grandes expositores de la ciencia judiciaria -Ptolomeo, Al-Bīrūnī, Aben Ragel, Abü Ma 'šr. Las disquisiciones genetlíacas $^{2}$ del autor (que debemos considerar anónimo, ya que

${ }^{1}$ Cf. Julián Ribera y Miguel Asín Palacios, Manuscritos árabes y aljamiados de la Biblioteca de la Junta, Madrid, 1912, pp. 112-114.

${ }^{2}$ Juan Vernet, Astrologia y astronomía en el Renacimiento. La revolución copernicana, Ariel, Barcelona, 1974, y La cultura hispanoárabe en Oriente y Occidente, 
Abdala posiblemente fue tan sólo uno de los usuarios del códice) son, pese a su alcance intelectual limitado, de un interés particular frente a la obra de estos grandes maestros en el arte de la predicción astrológica. Como ya adelantamos, el misterioso criptomusulmán es un verdadero experto en mujeres, cosa insólita en los libros decididamente masculinos de Ptolomeo y sus refundidores árabes. Nuestro morisco, rompiendo con las convenciones astrológicas más avaladas por la antigüedad, estudia por separado los doce signos zodiacales del hombre y de la mujer, y no es difícil ver que tiene una visión radicalmente distinta de ambos sexos. Para nuestra sorpresa, favorece a las féminas prácticamente en casi todos los renglones de la vida humana. Una lectura atenta del Tetrabiblos de Ptolomeo ${ }^{3}$, del Libro complido en los iudizios, de las

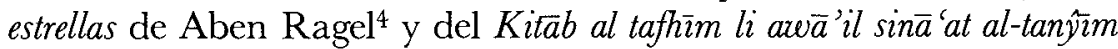

Ariel, Barcelona, 1978, explica que la astrología medieval europea, basada en las versiones de Ptolomeo y en las de los astrólogos árabes, se practicaba de acuerdo con tres métodos: el genetlíaco (Judiciis nativitatem), el sistema de las elecciones (que ayudaba a determinar el momento en que los astros ocuparían una posición favorable para emprender una acción determinada) y el sistema mundial, destinado a predecir catástrofes naturales y acontecimientos políticoreligiosos.

${ }^{3}$ Ptolomeo, en su célebre Tetrabiblos o Quadripartitum, habla de la mujer por referencia al hombre. Cuando hace alusión, por ejemplo, a la influencia de Marte y Venus sobre los habitantes de Libia, Numidia, Cartago y África, propone que éstos son "extremely ardent and disposed to commerce with women, so that even their marriages are brought about violent abduction", $T e$ trabiblos, ed. and tr. by F.E. Robbins and Williams Heinemann, Harvard University Press, Cambridge, 1940, p. 151. En otras ocasiones, el padre de la astrología sí parece referirse con más claridad a la mujer, aunque no a la manera del autor del ms. XXVI. Nos informa, por ejemplo, que la luna rige la matriz, que Saturno hace a las mujeres proclives a las enfermedades del útero, y que, cuando el sol está aspectado, la luna menguante y los planetas maléficos se acercan a sus grados subsiguientes, los hombres que nazcan serán privados de sus órganos sexuales y las mujeres serán estériles (ibid., pp. 325-327). Para el problema de la influencia de Ptolomeo en el mundo islámico y occidental, véase LynN THORNDIKe, A history of magic and experimental science, Nueva York, 1929.

${ }^{4}$ El célebre Aben Ragel o Abū-l-Hasan'Alī b. Abī Riŷāl al-Šaybāni -el Albohazam de los latinos - fue uno de los astrólogos más importantes de todas las épocas. Vivió entre los siglos x y xI de la era cristiana y su Kitāb al$b \bar{a} r i$ ' $\bar{\imath}$ a ahkām al-nuȳum, traducido por el judío Yehudá ben Mošé en la corte de Alfonso X bajo el título de Libro complido en los iudizios de las estrellas (editado por Gerard Hity en Madrid, en 1954), todavía se leía en España (y en la América recién descubierta) del siglo XVi. Julio Caro Baroja, Vidas mágicas e inquisición, Taurus, Madrid, 1967, t. 2, p. 209 y Julio JiméNez RueDA, Herejias y supersticiones en la Nueva España, Imprenta Universitaria, Méxi- 
(Libro de la instrucción en los principios del arte de la astrología) de Al-Bīrūnī ${ }^{5}$, nos lleva inmediatamente a la conclusión de que el morisco español no se pudo haber servido de estas figuras cimeras del arte de los astros para la elaboración de su curioso tratado de sortilegios. Lamentablemente, sólo cita como autoridad a un enigmático "sabiyo" "6 que debe haber sido el presunto autor del original árabe que, con toda probabilidad, está traduciendo.

¿Cuál es, entonces, la tradición genetlíaca que antecede a nuestro autor? Tengamos presente que los moriscos que escribieron a lo largo de los siglos XVI y XVII, en el momento de su agonía cultural y religiosa, casi nunca fueron escritores originales. Es que no les interesaba serlo. Querían, en la gran mayoría de los casos, salvaguardar lo poco que quedaba de la prestigiosa cultura de sus

co, 1946, pp. 214-216, nos dan noticia de la lectura del sabio musulmán por parte de Juan Betete (México, hacia 1582) y del arquitecto Melchor Pérez de Soto (1606-165?). Por su parte, Juan de Pineda, en sus Diálogos de agricultura cristiana (BAE, Madrid, 1963, t. 2, diálogo X, cap. XXII) se sirve de pronósticos de Aben Ragel. Sobre Aben Ragel, véanse los estudios de G. HiLtY, "El libro complido en los iudizios de las estrellas", AlAn 20 (1955), 1-74; J. VERNET, Estudios sobre la historia de la ciencia medieval, Barcelona-Bellaterra, 1979; C. Brockelmann, Geschichte der arabischen Literatur, Leiden, 1937, núm. 1, supl., p. 401 y H. Suter, Die Mathematiker und Astronomen der Araber und Ihre Werke, Leipzig, 1900, p. 100.

${ }^{5}$ El citado Tafhīm de Al- Bĩrūn̄̄ (Abū'l-Rayhān Muhammad ibn Aḥmad al-Bīrūmē, n. 362/963) está concebido para un público estrictamente masculino, no empece -y ello es muy elocuente- haberlo dedicado a una mujer: Rayhāna, ampliamente conocida por su sed de sabiduría científica. La discreta Rayhāna no hubiese podido encontrar información adecuada acerca de sus propias interrogantes personales al hojear el texto dedicado a ella con tanto respeto intelectual. Lo que encontraría serían datos como éstos: los nativos de Géminis, Sagitario y Capricornio habrán de tener la barba hermosa o larga, mientras que el signo de Cáncer hará a sus hijos buenos marineros, el signo de Leo buenos caballeros y halconeros y el signo Virgo buenos visires y eunucos. No hay lugar pues para la discreta Rayhāna en el Tafhīm de su devoto AI-Bīrūnī. Para más detalles sobre la vida y la obra de Al-Bīrūnī, cf. R. RAMSAY WRIGHT, $A$ book on instruction in the elements of the art of astrology, Luzac, Londres, 1934.

${ }^{6}$ Cf. los folios 33r, 34v, 49r, 52r, 54r, 57v, 60v, 62r, 65r. Aunque, en términos generales, el morisco refundidor habla de "Du-l-Qarnayn" como autor, al menos, de una porción de su texto, lo cierto es que en otros pasajes hace clara referencia al misterioso "sabiyo" y aun a otros autores, que menciona por nombre. El "šabiyo" astrólogo tampoco sería, por otra parte, Māšà'allāh ni el erudito judío de Toledo, Abraham ibn'Ezra, cuyos complejísimos textos judiciarios, tan distintos del de nuestro autor aljamiado, acaba de traducir al español Demetrio Santos: véase Mashahallah-Ben Ezra. Textos astrológicos medievales. (Ángulos, ciclos, casas e interpretaciones), Barath, Madrid, 1981. 
mayores, y por eso casi siempre son traductores o refundidores. El autor del códice propiedad de Abdala de Cosuenda no es, en este caso, una excepción ${ }^{7}$. No debemos estar ante un innovador original que se rebela contra el punto de mira excesivamente masculinizado de estas grandes autoridades en astrología genetlíaca. Antes, nuestro morisco parece cerrar filas con una tradición judiciaria bastante más modesta, que le vendría, por cierto, como anillo al dedo en las condiciones deterioradas en que se encontraba su propia cultura árabe en la España renacentista. Se trata de una modalidad astrológica en la que se atiende por separado los signos astrológicos de los hombres y los de las mujeres, en términos muy parecidos a los de nuestro morisco. Estos textos, conocidos casi siempre por el título técnico de Kitáb mawāîdial-riȳal wa-'l-nisā' (Libro acerca de la natividad de los hombres y de las mujeres), son casi siempre anónimos y espurios y se suelen atribuir a Ptolomeo, a Hermes y, sobre todo, a Abū Ma ${ }^{\natural}$ sar, que es el Albumasar de los cristianos $^{8}$.

Con el fin de estudiar el texto astrológico del morisco español en sus propios términos, adquirimos, gracias a la invaluable ayuda de nuestro colega Reinhold Kontzi, copia de uno de estos códices inéditos: el manuscrito Ldbg. 1002 de la Biblioteca de Berlín (Biblioteca Regia Berolinensis) ${ }^{9}$, que pretende, como tantos otros, la autoría de $\mathrm{Ab} \overline{\mathrm{u}} \mathrm{Ma}$ ‘ $\stackrel{\vee}{\mathrm{s}}$ ar. El espurio Albumasar, exacta-

${ }^{7}$ Los pasajes testimoniales más interesantes de la literatura aljamiadomorisca los he encontrado en dos autores: el Mancebo de Arévalo, cuya Tafsìra edita María Teresa Narváez bajo mi dirección como tesis doctoral de Estudios Hipánicos en la Universidad de Puerto Rico, y el anónimo refugiado de Túnez, cuyo fascinante texto misceláneo voy a editar en colaboración con mi colega de Oviedo Álvaro Galmés de Fuentes para la Colección de Literatura Aljamiada y Morisca de Gredos en Madrid.

${ }^{8}$ Richard Lemay, Abu Ma 'shar and Latin Aristotelism in the twelfth century. The recovery of Aristotle's natural philosophy through Arabic astrology, American University of Beirut, 1962, considera a Abū Ma'sar (Abū Ma'sar benMuhammad ben'Umar al-Balj̄i, muerto en 886) como el más importante astrólogo del Islam. D. Pingree adjudica el entusiasmo de Lemay, que le parece excesivo, al hecho de que el estudioso sólo conoce las traducciones latinas del sabio. Abū Ma“sar no le merece mucho respeto a Pingree: critica su "astonishing and inconsistent eclecticism" y concluye que "he is not to be ranked among the great scientists of Islam" ("Abu Ma š shar al- Balkhi, Ja "far ibn Muhammad", en Dictionary of Scientific Biography, Charles C. Gillispie (ed.), Scribner, Nueva York, 1970, pp. 32 y 35.

${ }^{9}$ Las siglas distintivas del códice son las siguientes: "Ms. Ldbg. 1002, Sprenger 1878, Volls 7; Bibliotheca Regia Berolinensis (Staats-bibliothek Prenss. Kulturbesitz, Orientabteilung) 1878 a. An horoscope and nativities, ascri- 
mente igual que nuestro morisco, considera por separado las constelaciones del hombre y de la mujer. Su cultura astrológica es igualmente modesta: nada de elucubraciones astronómicas complicadas ni de cómputos matemáticos sofisticados. Hemos traducido del árabe la constelación de Leo, y su contraste con nuestro manuscrito es, como tendremos ocasión de ver, muy interesante.

Con unas modestas herramientas lingüísticas (un castellano plagado de aragonesismos y de arabismos, que a menudo traduce a medida que avanza el texto), nuestro morisco se lanza a la ingente tarea de determinar las características de los hombres y de las mujeres de acuerdo con la influencia de los doce signos del zodíaco, que identifica sólo por el mes: Aries es abril; Tauro, mayo; Géminis, junio, y así sucesivamente. El autor suple unos breves datos astronómicos relativos a cada signo: si es de fuego, tierra, aire o agua; masculino o femenino; estival o invernal; frío o caliente; el planeta que lo rige, entre otros datos. Luego nos habla del tipo físico que ostentará el nativo (o la nativa) de cada signo, y sus marcas y lunares característicos. Se detiene bastante en las cualidades morales de sus clientes, así como en el tipo de relación que tendrán con el sexo opuesto; las enfermedades que los aquejarán; los hijos que procrearán; su ocupación o estado y sus experiencias de la vida general como viajes y riñas familiares. (Aunque nuestros lectores no sean creyentes en la ciencia judiciaria, sospechamos que más de uno buscará bajo su signo lo que el morisco le hubiera predicho de haber asistido a su consultorio en la España renacentista).

Toda una forma de vida, aunque esquematizada y borrosa, va surgiendo ante nuestros ojos cuando consultamos los horóscopos del códice aljamiado. Sabemos que la mujer Leo es rubia; que el hombre Virgo posee hermosos ojos; que el varón Escorpión es muy engañoso y el Capricornio muy reservado; que el hombre de Cáncer pasará la mar en barco pero volverá sano. Parecería que atisbamos "a través de un cristal, oscuramente" algo de la vida y características de la comunidad morisca del Siglo de Oro español. Pero no nos llamemos a engaño: nuestro autor debe estar copiando un texto árabe que acaso lo que reflejó fue la vida

bed to Abú Ma'shar, 150 pp.". Resulta curioso consignar el hecho de que en el catálogo de Fuat Sezgin, tan útil para el investigador, el manuscrito no aparece citado; acaso haya cambiado el número de la catalogación o haya escapado a la atención de Sezgin por ser de más reciente adquisición. Cf. SEzGrN, Geschichte des arabischen Schriftums, Bd. VII, E.J. Brill, 1979. 
del Cairo o de la Bagdad de los siglos medios ${ }^{10}$. Lo que no deja de ser interesante es el hecho de que estos antiguos modelos de vida del Islam oriental se intentaron aplicar a la vida empobrecida de la minoría desacreditada que tradujo amorosamente el códice y que tantas veces lo pondría en práctica. Sólo en muy pocos casos advertimos que las circunstancias históricas de la España del Siglo de Oro podrían desmentir los reclamos del códice. El autor, por ejemplo, asegura al hombre Capricornio que será "oficial de la alŷama'a", oficio poco probable bajo la égida del tribunal de la Inquisición, que había desmantelado por edicto todo rastro de vida islámica en la Península. Y, con todo, hay que recordar que la ocupación de oficial de la aljama aún sería plausible en la España renacentista, sobre todo entre los moriscos aragoneses, que no se vinieron a convertir colectivamente hasta entrado el siglo XVI.

Vayamos ahora al caso físico de los demandantes que atiende el dueño del códice. Los hombres tienden a ser mucho más oscuros de tez que las mujeres (los Leo son "eskuro[s]"; los Piscis y Acuario, cobrizos), mientras que a las afortunadas féminas se les adjudica, invariablemente, el color blanco, frecuentemente entreverado de rojo y de amarillo, como exigían los estetas musulmanes, cual Nefzā $\bar{w}^{11}$. Curiosamente, ninguna mujer del códice es morena (cosa harto dudosa entre la morería española) y los únicos cabellos cuyo color se indica son los de las mujeres nacidas bajo Leo y Aries, y son, contra todo lo esperado por el clisé de la agarena guapa, amarillos ${ }^{12}$ y rojos, respectivamente. Parecería que nuestro autor se atiene más a fantasías estéticas que a la realidad objetiva al hablarnos en su texto de moriscas de colora-

${ }^{10}$ Insiste con toda razón Anwar Chejne en que la literatura aljamiada, por lo general, se sirve de textos árabes originales y pocas veces es, como en el caso del Mancebo de Arévalo, poderosamente original. Cf. su libro póstumo Islam and the West. The moriscos. A cultural and social history, State University of New York Press, Albany, 1983, p. 96.

${ }^{11}$ Cf. 'UMar IBN MUhammad AL-NAFZĀWī, The glory of the perfumed garden. The missing flowers, Neville Spearman, Londres, 1975.

12 Tenemos documentadas moriscas rubias en el siglo XVI. La morisca Cándida la Rubia parece haber sido conocida por el color de oro de sus cabellos y por otras cosas menos halagadoras, como el haber incitado a una vecina cristiana a convertirse al Islam. Cf. Jacqueline Fournel Guérin, "La femme morisque en Aragon", en Les morisques et leur temps, Table Ronde Internationale, Éditions du Centre Nacional de la Recherche Scientifique, Paris, 1983, p. 528 . 
ción exótica. ¡Cuánto debió, con ello, halagar a sus modestas correligionarias!

Nuestro tratado carga la mano, a diferencia de otros discursos astrológicos, en la belleza de los ojos de sus clientes. Son ojos que se nos antojan más representativos del tipo físico que solemos asociar a los hijos de Agar: tanto el hombre Géminis como el Libra tendrán ojos y pestañas hermosos; el de Leo, los ojos "pintados" y las pestañas profusas, mientras que la mujer nacida en Acuario será poseedora de lindos ojos, y la de Libra, de lindas cejas.

Lo que sí llama mucho la atención en el códice es la cantidad de marcas, huellas de heridas y lunares que exhiben las hembras y los varones en su piel. Muchas de ellas nos hablan de una vida prosaica pero particularmente violenta. El hombre Piscis tiene una cicatriz de quemadura en la cara y el Escorpión una huella de herida en la cabeza, mientras que la mujer Leo, por su parte, conserva rastro de mordida de perro en el cuerpo. (Con curiosa modestia, el autor, que había adjudicado lunares y marcas de nacimiento en el sexo a los hombres, jamás aludirá a las partes privadas de las mujeres. ¿Lo haría para evitarles un momento difícil en la intimidad de su consultorio?)

En el códice aljamiado, los hombres hermosos sobrepasan numéricamente a los feos. Se destacan de manera especial las dotes físicas agraciadas del varón Aries, Géminis, Virgo, Libra, Escorpión, Sagitario, Capricornio y Acuario. (Hay que decir que los nacidos bajo Géminis y Sagitario se llevan la palma de la hermosura.) Algunos de estos signos, sin embargo, mezclan las características atractivas con defectos físicos evidentes. Al nativo de Libra lo afea una nariz un poco tuerta; el de Capricornio resulta delgado de cuerpo y el de Acuario presenta un vientre distendido. ¿Y las mujeres? Aquí viene la primera gran sorpresa de nuestro códice. Rompiendo la tradición de Ptolomeo, Al-Bīrūnī y de los pseudo Abū Ma ${ }^{\vee}$ sar, el morisco las declara invariablemente más hermosas que los hombres. Podemos decir que no hemos visto nunca un texto genetlíaco que favorezca de tal manera a las mujeres como el que estamos estudiando en estas páginas. El sitial que ocupa la mujer en este códice, a despecho de la larga tradición islámica (y, dicho sea de paso, occidental) de minimización de la mujer, constituye uno de sus misterios - y de sus encantosmás inesperados.

Pero no perdamos de vista las características físicas de las mujeres del manuscrito Junta XXVI. A pesar de que el autor dedica menos folios a la consideración de las féminas, advertimos en se- 
guida que less is more. Se celebra sin ambages la belleza de la mujer nacida en Aries, en Géminis, en Leo, en Libra, en Escorpión, en Sagitario y en Acuario. Pero he aquí lo más sorprendente: no hay ni una sola fea en todos los signos zodiacales. ¡Qué suerte para las moriscas demandantes de Abdala! Sólo la mujer Libra tiene un rasgo que podría parecer de dudoso atractivo: "abrá algunoš foradikoš [hoyitos] en šu kara" (fol. 77v). Y, con todo, es de ver el cariño con el que se describen estas señas en la piel, como si hicieran gracioso el rostro en vez de afearlo.

Las demandantes del Abdala se sentirían más que satisfechas al conocer el designio de los astros sobre sus características morales e intelectuales. Sobre todo si acudían a la consulta acompañadas de un varón cuyo horóscopo pudiera contrastar con el suyo. Una vez más, las féminas llevan las de ganar, ya que son, invariablemente, mejores personas que los varones. Con una misteriosa generosidad, el autor considera prácticamente perfectas a las mujeres - siempre sus preferidas - nacidas bajo cada uno de los signos del zodíaco. En cambio, sólo los varones de Libra y de Géminis suelen ser absolutamente virtuosos, sin tacha en su condueta. Las mujeres, por su parte, se distinguen por sus virrtudes en el campo afectivo: la nativa de Piscis será mujer de paz y de perdón, que "fará biyen i derremirá [redimirá]el mal" (fol. 84v); mientras que la ariana "obrará en biyen i šerá ke fará biyen kon šuš biyeneš" (fol. 68r). El morisco parece tener un concepto de la mujer tan alto que la venera de manera cuasi religiosa, empleando para su descripción adjetivos píos que no adjudica jamás a los varones. Así, las nacidas en Géminis, Aries y Acuario serán "biyenabenturada[sl]", de "dotirina bendiyta" (fol. 68v), "de muchas señaleš i marabillaš" (fol. 71r).

El único defecto significativo que exhiben las féminas del tratado es que suelen tener mal genio. Pero, invariablemente, son prestas a apaciguarse: Aries, Géminis, Cáncer, Leo, Escorpión, Acuario y Capricornio. La más brava parece ser la nacida bajo Escorpión, y, con todo su mal carácter, es de "buwen apagar" (fol. 78v). Salta a la vista que el genio fuerte femenino se encuentra siempre templado, y que no constituye, por ello, un defecto grave. Esto no ocurre en el texto astrológico berlinense del putativo Abū Ma'šar: allí vemos que, en la mayoría de los casos, cuando una hembra es irascible, no hay quien la soporte. Sólo en poquísimas ocasiones las mujeres del ms. XXVI muestran un tipo distinto de imperfección moral: la pisciana parece proclive a la envidia, mientras que la capricorniana y la geminiana son 
celosas. Tampoco parece que estemos ante una falla de personalidad seria. Cuando el autor describe, por ejemplo, a la nativa de Géminis como "de muchos selos sobre su marido i sobre los suyos"' (fol. 70r), casi parecería que celebra su dedicación al afecto de su familia. Comparemos esto con los defectos de carácter que aquejan al sexo fuerte: el varón de Aries es codicioso; el de Tauro, torpe y lascivo; el de Géminis, un hechicero de tal calibre que embrujará a sus propios hijos; el de Cáncer, de poca honra; el de Leo, flojo; el de Virgo, fácil al enojo; el de Escorpión, de poco aguante y muy engañoso; el sagitariano, propenso a las peleas; el nacido en Capricornio, tacaño, engañoso, lleno de ardides, reservado; mientras que el nativo de Acuario parecería incluso ser algo neurótico, ya que se le describe como pensativo y triste.

El morisco "feminista" nos tiene reservada ahora la mayor de las sorpresas: la mujer de su tratado astrológico es tan inteligente o más que el hombre. Se describe la agudeza de los varones nativos de Géminis, Virgo, Sagitario y Acuario, mientras que las hembras nacidas bajo las constelaciones de Aries, Leo, Virgo, Escorpión y Sagitario son tanto agudas como "de fuwerte kabesa", discretas y de "buwen švo" (es decir, además de inteligentes, equilibradas). Ninguna clienta de Abdala se vio jamás humillada por un horóscopo que pusiera en duda su capacidad intelectual. Ojalá ninguna morisca hubiese ido a la consulta astrológica acompañada por algún amigo o pariente varón nacido en Aries o en Tauro, ya que pasaría la vergüenza de ver al primero descrito como "simple", (fol. 34v) y al segundo como "torpe"' (fol. 37r). Pero no creamos que el morisco violenta del todo la narración judiciaria islámica que le precede al favorecer de tal manera a sus clientas. Curiosamente, el pseudo Abü Ma`šar del códice de Berlín celebra, en pefecta coincidencia con nuestro criptomusulmán, la inteligencia de alguna de sus mujeres. Describe, por ejemplo, a

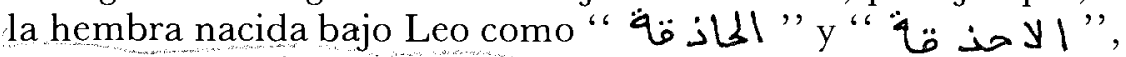
de $h \bar{a} d i q(\ddot{\jmath}$ ), término que J. M. Cowan traduce como "skillful, skilled, proficient, well-versed, clever, smart, intelligent"'13, y Maurice G. Kaplanian como "práctico, diestro o inteligente"' 14 . No es difícil imaginar que Fray Luis de León, Fray Hernando de Talavera y Juan Luis Vives se hubieran horroriza-

${ }^{13}$ Arabic-English Dictionary, 3rd. ed., Spoken Languages Services, Ithaca, Nueva York, 1976, p. 164.

${ }^{14}$ Alhambra. Diccionario español-árabe/árabe-español, Sopena, Barcelona, 1979, p. 95. 
do ante tal despliegue de atributos intelectuales femeninos ${ }^{15}$.

El varón del tratado genetlíaco suele exhibir un defecto que no veremos nunca entre las hembras: es sensual y libidinoso. E1 nacido en Tauro, Libra, Leo y Cáncer es un gran amador de las mujeres. El único indicio, en cambio, que tenemos de una líbido fuerte de parte de la mujer es el caso de la nacida en Tauro -y regida, entonces, por Venus-, de quien se dice que "el mes de su kašar es en-biniyéndole su folor' (fols. 70v-70r). Probablemente, el astrólogo recomienda a la taurana un matrimonio temprano (tan pronto le venga su "folor" o ciclo menstrual), de manera que pueda dar cauce inmediato a su sensualidad venusina. Nada más aceptable socialmente.

En nuestro texto, el hombre suele contraer matrimonios múltiples. Todos casan con dos o tres mujeres, menos el nativo de Escorpión, que se circunscribe a una ${ }^{16}$. En cuanto a las hembras,

${ }^{15}$ Casi todos los tratadistas españoles de la época que se ocupan de la mujer dan por sentada su inferioridad física, intelectual y moral. JUAN Luis VIVES, en su Libro llamado instrucción de la mujer cristiana (1524), es particularmente severo: insiste en que debe aislarse a la hembra del sexo opuesto, incluso de sus hermanos, y que debe vivir sólo para guardar la castidad. El portugués Francisco Manuel de Mello aconseja a la mujer que oculte su inteligencia, si es que la tiene (Guía de casadas). Ya sabemos que Fray Luis, irremediablemente misógino pese a su buena voluntad, restringe a su perfecta casada al ámbito estricto del hogar, e incluso llega a suponer que ésta no tiene necesidad de gastar en alimentos, ropa y afeites tanto como el hombre, ya que tiene menos calor natural que el sexo contrario. P.W. Bomli resume el tenue feminismo de los autores más arriesgados del Renacimiento español en su estudio La femme dans l'Espagne du Siècle d'Or, Martinus Nijhoff, The Hague, 1950: a lo más que llegan es a postular el derecho de la joven a elegir marido y a defender su honor, pero nunca el derecho a cultivar su inteligencia. Ya sabemos lo duro que fue Lope de Vega con Nise cuando ésta quiso descollar intelectualmente en La dama boba y lo intolerante que fue Calderón de la Barca en sus comedias Guárdate del agua mansa y No hay burlas con el amor. Parecería que sólo Sor Juana se hubiera sentido satisfecha con el inesperado feminismo intelectual de nuestro anónimo astrólogo musulmán.

${ }^{16}$ La enorme consistencia con la que el morisco predice para los varones un matrimonio pluralista parecería reflejar una sociedad típicamente islámica. Y sin embargo el texto sería aún aplicable a la España criptomusulmana del Siglo de Oro: Raphaël Carrasco y Bernard Vincent nos documentan algunos casos de moriscos casados simultáneamente con varias mujeres a lo largo del siglo XVI. Con todo, los moriscos no fueron masivamente polígamos, principalmente por razones económicas. La vigilancia extrema a que la Inquisición sometía a la casta perseguida también constituiría un freno para estos matrimonios que la oficialidad cristiana consideraba ilegítimos. Cf. CARrasco y VinCENT, "Amour et mariage chez les morisques", CALIE, pp. 137 ss. 
tan sólo en una ocasión se nos deja saber que se casan con varones que tengan (o hayan tenido) otras esposas: es como si el morisco quisiera proteger a sus clientas de la noticia, siempre desagradable para la mujer, de que habría de compartir a su hombre.

Los varones del ms. XXVI, igual que los del pseudo Abū

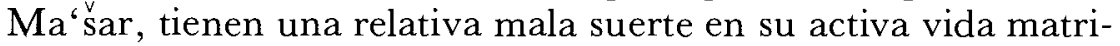
monial. El ariano tendrá problemas en su boda; el geminiano, "peleyto por parte de muŷereš", (fol. 42r); mientras que al canceriano incluso lo llega a hechizar una mujer pecosa.

Las féminas del texto son, en cambio, afortunadísimas en lo tocante a su experiencia nupcial. Siempre se $\operatorname{casan}^{17}$, y tan sólo a la nativa de Tauro se le predice un " kašar kerebado [quebrado, angustioso] o menguado" (fol. 70v). Pero estas hembras paradigmáticas suelen, para su dicha, amar a sus maridos y concordar bien con ellos. No hay una sola que sea infiel. ¿Wishful thinking o mandato subliminal del astrólogo al sexo opuesto? Como quiera que sea, las jóvenes podían acudir más que confiadas a la consulta de Abdala: todo serían buenas noticias en el renglón matrimonial.

¿A qué se dedican los personajes hipotéticos del ms. XXVI a quienes el morisco levanta horóscopos? Las actividades fundamentales son la labranza y la ganadería, y, en menor grado, el comercio. Ha quedado atrás la sofisticación y la variedad de las ocupaciones de los clientes de Ptolomeo y Al-Bīrūnī, que eran filó-

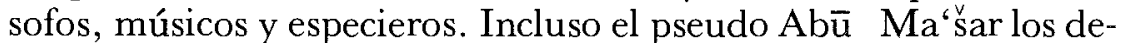
clara príncipes bajo ciertas constelaciones afortunadas. Pero las noticias prosaicas que nos da el texto aljamiado en lo tocante a los oficios de sus usuarios serían más que adecuadas para el consumo de la casta morisca empobrecida del Siglo de Oro español.

Las ocupaciones más "sofisticadas" que Abdala asigna a sus clientes son las de oficial de la aljama (Capricornio) y la del comentador del Corán (Piscis). Este último oficio tendría que haber sido llevado a cabo en el más estricto secreto, y se sabe que costó la vida a más de un criptomusulmán en el siglo XVI.

¿Y la mujer? En lo fundamental se nos confirma su pertenencia al mundo rural y agropecuario que había caracterizado a su contrapartida masculina. Se destacarán, sin embargo, más en las

${ }^{17}$ Seguramente por descuido, el autor no nos ofrece detalles acerca del matrimonio de las nacidas bajo Piscis y Leo, pero dados los hijos que tienen y el alto estado que alcanzan, podemos presuponer sin temor a exagerar que se habrían casado bien. 
mercaderías que en las faenas agrícolas: serán hábiles comerciantes las nacidas en Cáncer, Capricornio y Acuario. La nacida en mayo bajo Tauro llegará a tener, incluso un oficio: " abrá en šu poder ofisiyo de ke se aporobechará kon él"' (fol. 69v). Todo ello obedece perfectamente a la realidad socioeconómica de la morería española, como nos demuestra Jaçqueline Fournel Guérin ${ }^{18}$. En el ms. XXVI nos encontramos, incluso, con muchas ricas herederas, tal las nacidas bajo Cáncer, Escorpión, Capricornio y Piscis. El astrólogo dramatiza la fortuna personal de las nacidas bajo Libra y Sagitario al asegurarles la posesión de joyas ${ }^{19}$ y de un rango social elevado ${ }^{20}$. Increíble pero cierto: absolutamente todas las mujeres del códice, no importa bajo qué signo astrológico hayan nacido, son pudientes y socialmente distinguidas. Para colmo, a los varones no les acaece casi nunca semejante fortuna, sino que tienen, por el contrario, una notoria mala suerte en sus finanzas y en su rango social. El autor, quién sabe con qué misterioso ajuste de cuentas, predice la pérdida de la hacienda a los hombres de casi todos los signos del zodíaco ${ }^{21}$. Pero es que hay más: varios

18 La investigadora nos indica la presencia de mujeres amortajadoras, sanadoras, comerciantes y dueñas de hospederías en la Zaragoza del siglo XVI. María Albora de Belchite, morisca de cincuenta años, enseñaba el islam a las mujeres de la villa y cobraba por ello; María Fierro de Nabal y María Ortega eran amortajadoras; Esperanza Alguazí de Aytona administraba las fadas a los recién nacidos; María Jiménez de Zaragoza y María de Ubécar atendían albergues u hospederías en Brea; mientras que Jerónima de Muza, pese a que estaba prohibido a la sazón a los moriscos vender alimentos, atendía un negocio de carnicería (op. cit., p. 525).

${ }^{19}$ Las moriscas cristianas nuevas procesadas por la Inquisición eran castigadas a una pena que debió hacerlas sufrir mucho: perdían el derecho a portar joyas. Tenemos documentados, sin embargo, bastantes procesos que nos dejan ver cómo las mujeres desobedecían la pragmática. Cf. Fournél GuÉRIN, op. cit., y L. López-BARALT, "La angustia secreta del exilio. El testimonio de un morisco de Túnez", HR 55 (1987), 41-57.

${ }^{20}$ Aly MAZAHÉri, La vie quotidienne des musulmans au moyen âge. Xe au xiïie siècle, Hachette, Paris, 1951, pp. 61-68, explora el hecho de que en el mundo árabe de los siglos XI y XII algunas mujeres estudian carreras liberales: profesoras, abogadas, poetisas, astrólogas, médicas, institutrices, enfermeras e incluso aduaneras. Algunas llegan a ser jefas de Estado, como sucede en El Cairo y Delhi. Se trata, sin duda, de excepciones, ya que, en las esferas menos privilegiadas, las vemos cumplir con faenas más acordes con las que describe nuestro manuscrito: obreras, ganaderas, tejedoras, tintoreras, lavanderas. Salta a la vista que el salario del marido no era suficiente y que las esposas tenían que completarlo con su esfuerzo laboral.

${ }^{21} \mathrm{El}$ autor predice al hombre nacido bajo Virgo una buena herencia, con la que tendrá placer, pero añade más tarde, contradiciéndose, que no herede- 
de estos varones, aparentemente faltos de criterio en materia fiscal, habrán de depender económicamente de las mujeres. Sería fascinante saber si estamos ante el reflejo (siquiera exagerado) de unas coordenadas fiscales de índole histórica o ante un prejuicio feminista de enormes proporciones por parte del autor del manuscrito aljamiado.

Nuestro astrólogo ha cargado la mano demasiado en la buena fortuna que le deparan los astros a las mujeres. No empece el hecho de que dedique más folios a explorar el horóscopo de los varones, éstos resultan, en su conjunto, claramente inferiores a su contrapartida femenina. Aun cuando se celebra la belleza de algunos de sus rasgos físicos, los hombres tienen mucho más defectos corporales que las hembras. Asimismo, exhiben más imperfecciones morales, y de naturaleza mucho más grave que ellas. Mujeres y hombres compiten en inteligencia - cosa inaudita en el Siglo de Oro español - y sólo van a ser hombres los considerados, sin piedad alguna, como torpes. La vida de los varones del tratado, obedeciendo en este caso a una realidad histórica y social incontrovertible, es más interesante y variada que la de las mujeres, sólo que ello no parece servirles de mucho, ya que tienen tensiones más profundas (guerras, heridas, porfías) que las hijas de Eva. Los miembros del sexo fuerte suelen depender económicamente de las hembras, y pierden su hacienda, como vimos, en ocho de los signos astrológicos. Frente a estos desbarajustes económicos, nos encontramos en el códice una y otra vez con féminas acaudaladas y de innegable prestigio social. Los varones, disipados e inmaduros si vamos a hacer caso al autor del tratado genetlíaco, presentan, por otro lado, frecuentes problemas matrimoniales, que contrastan con la armonía conyugal de las clientas femeninas del maestro astrólogo.

¿Por qué el autor del códice, quienquiera que haya sido, privilegia de tal manera a las mujeres? O era un inesperado feminista avant la lettre -el primero en la España misógina del Siglo de Oro- o era un hábil negociante que se esmeraba por mantener contentas a sus clientas del sexo bello ${ }^{22}$. Es posible que el maes-

rá nada de sus progenitores y que lo perderá todo. Una vez más, descuidos como éste son usuales no sólo en nuestro códice aljamiado sino en los tratados astrológicos más sofisticados.

22 ¿Cuánto cobraría nuestro astrólogo por su consulta? Difícil saberlo, ya que el manuscrito no ofrece datos internos que permitan calcular el importe de sus horóscopos. Éste debió haber sido bastante alto, sin embargo, si el morisco emuló a sus antepasados musulmanes. Algunos astrólogos medievales pre- 
tro judiciario haya tenido una clientela predominantemente femenina. O acaso esta consulta de muchachas casaderas la haya atendido una morisca y no un morisco. Recordemos que las mujeres moriscas fueron las guardianas principales de las tradiciones islámicas en el hogar, y que muchas enseñaban incluso ciencia coránica en sus comunidades ${ }^{23}$. Las féminas astrólogas están, asimismo, documentadas en la tradición musulmana. La posibilidad de que haya habido astrólogas usuarias del códice (que pasaría de mano en mano) no es nada remota. ¿Sería posible, por otra parte, explicar la clara inclinación pro-femenina del texto en términos de que hubiese sido una mujer y no un hombre la refundidora que arreglara el tratado pro domo sua? Esto acaso sería más difícil, pero tampoco del todo inaudito, si recordamos los testimonios de moriscos como el Mancebo de Arévalo, que se dejaba iluminar por la sabiduría intelectual de las hembras criptomusulmanas de su comunidad (como la Mora de Úbeda y Nozeita Calderán, esta última, astróloga), de las que se dejó aleccionar nada menos que en materia coránica ${ }^{24}$. Acaso nunca sepamos a ciencia cierta quién ajustó el tratado astrológico a los intereses femeninos ni exactamente por qué lo hizo. También es muy difícil saber si la modalidad feminista del tratado fue obra de refundidor morisco o si éste ya heredaría el texto árabe con sus espléndidos, inesperados prejuicios a favor de la mujer, tan preferida por aquellos siglos. Sea como fuere, podemos pensar que los astros benévolos que garantiza el códice a las féminas moriscas les habrían ayudado a aliviar en algo las terribles tensiones bajo las que vivían en el ocaso de su vida colectiva. Ya sabemos que a la hipo-

tendían adivinar quién había llevado a cabo un robo, y un antiguo proverbio árabe reza: "māfăt'ala'l-sāriq šall-uh al-munaŷŷim" ("lo que el ladrón no se llevó se lo llevó el astrólogo"). Serían, pues, muy altos, los honorarios de los predecesores de nuestro morisco. Cf. R.B. Serjeant, "Islam", en Oracles and divination, Michael Loewe and Carmen Blacker, Shambala, Boulder, 1981, p. 229.

${ }^{23}$ Fournel Guérin, op. cit. y Mercedes García Arenal, Inquisición y moriscos. Los procesos del tribunal de Cuenca, Siglo XXI, Madrid, 1978, meditan a fondo sobre el importante papel que la mujer desempeñó como mantenedora de la tradición, costumbres y ritos, y como transmisora de las enseñanzas musulmanas.

${ }^{24}$ Cf. L.P. HARVEY, "El Mancebo de Arévalo y la literatura aljamiada", en Actas del coloquio internacional sobre literatura aljamiada y morisca, Gredos, Madrid, 1978, p. 40 y María Teresa Narváez, "Nozeita Calderán, partera y experta en el Corán", ponencia leída en el Tercer Congreso Internacional de Estudios Moriscos (Hammamet, Túnez, marzo de 1987), en prensa en la $R e$ vue d'Histoire Maghrébine. 
tética joven que invocamos al principio de estas líneas, Abdala de Cosuenda, guiado por su singular códice astrológico y violando la más elemental ley de probabilidades, le habría de pronosticar una vida perfecta. Y casi casi nos parecería ver a la muchacha abandonar el modesto consultorio con una sonrisa de felicidad en los labios.

Luce López-Baralt

Luisa Piemontese

Clatre Martin

Universidad de Puerto Rico

Yale University 